\title{
Pharmaceutical interventions in the mana
of tuberculosis in a pneumophtisiology department, Ivory Coast
}

This article was published in the following Dove Press journal:

Therapeutics and Clinical Risk Management

22 November 2016

Number of times this article has been viewed

\author{
Danho Pascal Abrogoua' \\ Boua Alexis Thierry Kamenan' \\ Brou Jean Marcel Ahui ${ }^{2}$ \\ Elisée Doffou ${ }^{3}$ \\ 'Department of Clinical Pharmacy \\ and Therapeutics, Faculty of \\ Pharmaceutical and Biological \\ Sciences, Félix Houphouët- \\ Boigny University, ${ }^{2}$ Department of \\ Pneumophtisiology, Teaching Hospital \\ of Cocody, ${ }^{3}$ Department of Pharmacy, \\ Teaching Hospital of Yopougon, \\ Abidjan, Cote d'Ivoire
}

Objectives: This study aims to analyze the profile and relevance of pharmaceutical interventions (PIs) in the management of tuberculosis (TB) at inpatient settings.

Patients and methods: Cross-sectional descriptive study conducted from March to December 2014 within the inpatient unit of pneumophtisiology department, Ivory Coast. Information collected was based on the classification of drug-related problems (DRPs) and PIs outlined by the French Society of Clinical Pharmacy. A score was assigned to each PI according to the importance of the potential clinical impact. This score was correlated with the severity of clinical consequences avoided by the intervention. The listing of interventions was made by pneumophtisiology specialists. The score assigned to each intervention ranged from 0 (without clinical impact) to 3 (vital clinical impact). The acceptance rate of interventions by physicians was evaluated.

Results: Of 130 patients, $28.5 \%$ received PIs. The main reasons for interventions were drugdrug interactions (26.4\%), noncompliance with recommendations (24.5\%), and adverse effects (24.5\%). Antituberculosis drugs were involved in $40.3 \%$ of DRPs. Interventions were predominantly proposals for monitoring treatment effectiveness and safety parameters $(52.7 \%)$ followed by proposals of therapeutic choice $(28.1 \%)$. All interventions were accepted by the physicians. Most interventions (59.6\%) were listed as interventions with significant clinical impact.

Conclusion: The presence of a pharmacist at inpatient setting has contributed to the prevention and resolution of problems related to the pharmacotherapeutic management of TB. Pharmacists can position themselves as major players in the therapeutic management of TB inpatient in resource-limited setting.

Keywords: tuberculosis, drug-related problem, pharmaceutical intervention, relevance, clinical impact, Ivory Coast

\section{Introduction}

Tuberculosis (TB) remains a large and growing health problem worldwide. In its 2014 report, the World Health Organization estimated that 9 million people developed TB and 1.5 million died from it, making this disease the second largest cause of death after HIV/AIDS. ${ }^{1}$ A large majority of these cases were in Asia, but the incidence of TB is highest in Sub-Saharan Africa, in some countries exceeding 300 cases per 100,000 inhabitants. ${ }^{2}$ Côte d'Ivoire is one of the Sub-Saharan African countries that has been most affected by TB, with an incidence in 2014 of 170 new cases per 100,000 population. ${ }^{1}$ In addition to drug resistance and HIV, ${ }^{3}$ poor quality of care for TB is another serious factor that continues to thwart measures taken worldwide against this disease. Assessment of the global situation has shown that clinicians often deviate
Correspondence: Danho Pascal Abrogoua Department of Clinical Pharmacy and Therapeutics, Faculty of Pharmaceutical and Biological Sciences, Félix HouphouëtBoigny University, 22 BP I397 Abidjan

22, Côte d'Ivoire

Tel +225 2l 07949478

Email abrogouadp@yahoo.fr (c) (1) (5) 2016 Abrogoua et al. This work is published and licensed by Dove Medical Press Limited. The full terms of this license are available at https://www.dovepress.com/terms.php BY NC and incorporate the Creative Commons Attribution - Non Commercial (unported, v3.0) License (http:///creativecommons.org/licenses/by-nd $3.0 /$ ). By accessing the work you
hereby accept the Terms. Non-commercial uses of the work are permitted without any further permission from Dove Medical Press Limited, provided the work is properly attributed. For permission

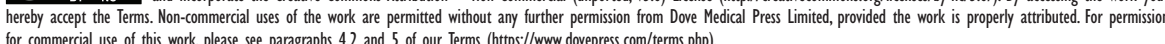


from internationally recommended standards for the treatment of TB. ${ }^{4}$ These include insufficient use of microscopic examinations for diagnostic purposes, usually associated with excessive confidence in radiography; use of nonrecommended TB treatments, with incorrect combinations of drugs; dosage and treatment errors; and a lack of supervision and adherence to treatment controls. ${ }^{4-6}$ Overall, these findings highlight flaws in care practices, which result in a below standard quality of treatment for TB for those populations most vulnerable to the disease. Improving the quality of care requires not only qualified, available, and motivated personnel but also integration of pharmacists into the health services setting.

With their extensive training and knowledge of drugs in terms of chemical and pharmacological properties, pharmacists are currently interested in the pharmacotherapeutic aspect of care. This pharmaceutical activity has given rise to patient-centered pharmaceutical practices, of which a key element is pharmaceutical interventions (PIs).

Among PIs, pharmaceutical analysis of prescription medications, defined in this study as a drug regimen review (DRR), contributes to improvement of the overall therapeutic response and patient safety. The goal of the DRR is to ensure that optimal patient outcomes are achieved from drug therapy. This includes consideration of the indications, effectiveness, and safety of each medication and the patient's compliance with drug therapy. The role of the pharmacist includes the identification, resolution, and prevention of drug-related problems (DRPs).

PIs have been demonstrated to have a positive influence on morbidity, the adverse effects of drugs, ${ }^{7,8}$ and reducing the cost of treatment. ${ }^{9}$

The purpose of the study was to evaluate the impact of clinical pharmacy activities within the inpatient unit of the pneumophtisiology department of the teaching hospital (CHU) in Cocody-Abidjan, Côte d'Ivoire, through analysis of the profiles of PIs and their relevance (acceptance rate and clinical impact) in the care of patients with TB.

\section{Patients and methods \\ Study design and setting}

We conducted a descriptive cross-sectional study from March to December 2014. This clinical pharmacy pilot study covered all TB inpatients in the pneumophtisiology department of CHU in Cocody-Abidjan during the study period. The study began after obtaining permission from the Cocody Teaching Hospital through its Medical Scientific Department. All patients gave their informed consent. The information collected on patients who were involved in the study remains confidential and anonymous. All persons having access to the data were required to maintain professional confidentiality.

\section{$\mathrm{PI}$ collection and classification tool}

The information collected was based on the classification of DRPs and PIs outlined by the French Society of Clinical Pharmacy. ${ }^{10}$ The data included patient characteristics (age, category, sex, diagnosis), identification of DRPs, drugs associated with DRPs, PIs, outcome of PIs, and listing of the clinical impact of PIs and their level of acceptance by physicians.

The main tool supporting data collection that we have called "dashboard" contained key information listed earlier after detecting a DRP.

\section{Study procedure}

During the study, the pharmacist integrated the healthcare team in analysis of all medical prescriptions in the context of a DRR.

The pharmacist conducted a prescription review with the possibility of viewing patient medical records together with patients' biological response and medical history, if these data were available and required analysis. When some information is not included in the medical record, the pharmacist sought such information from the physicians.

If we found that the therapeutic response, safety, efficiency, comfort, or cost of the treatment could be improved, we then developed a pharmaceutical opinion about the detected DRPs. The physician could accept or reject proposals made in the pharmaceutical opinion. If the opinion was accepted, the physician modified the treatment, if possible, and provided a rating of the clinical impact of the PI.

The DRR was done proactively (during medical rounds and staff meetings) or retroactively (by analysis of inpatients' records). Being limited to a proactive activity would be limited to an active presence of the pharmacist in his/her practice per day. Hence, a retroactive activity with the analysis of inpatients' medical records fills the rest of the daily time of the pharmacist.

The DRR was undertaken according to the following references: Vidal ${ }^{\circledR}$ Dictionary 2012, ${ }^{11}$ the Dorosz ${ }^{\circledR}$ guide $2013,{ }^{12}$ the 2013 drug interactions thesaurus of the French National Agency of Medicine and Health Products Safety, ${ }^{13}$ and the 2013 recommendations of the Côte d'Ivoire National Tuberculosis Programme. ${ }^{14}$

\section{Analysis of Pls and their clinical impact}

The potential clinical impact of each PI was interpreted using a score based on a particular listing. ${ }^{15}$ This listing 
was derived from those used in the USA by Bayliff and Einarson. ${ }^{16}$ In practice, a score was assigned to each PI according to the importance of the potential clinical impact of the DRP. This score was correlated with the severity of clinical consequences avoided by the PI. The scale used was the following:

(i) $\mathrm{PI}_{0}$ (PI without direct clinical impact, for financial or informational purposes only).

(ii) $\mathrm{PI}_{1}$ (PI with significant clinical impact; increases treatment efficacy and/or patient safety and/or improves patient quality of life).

(iii) $\mathrm{PI}_{2}$ (PI with very significant clinical impact; prevents organ dysfunction, avoids intensive medical supervision or irreversible sequelae).

(iv) $\mathrm{PI}_{3}$ (PI with vital clinical impact; avoids a potentially fatal outcome).

The evaluation of the clinical impact of PIs and scoring were performed by physicians specializing in pneumophtisiology.

\section{Evaluation of the relevance of Pls}

The relevance of each PI was defined as improving the care of patients. This was evaluated by means of two parameters ${ }^{17}$ : (i) PI acceptance rate, calculated as the ratio of number of PIs accepted by physicians to the total number of PIs and (ii) PI analysis according to clinical impact.

\section{Collaboration between physicians and pharmacists on the healthcare team}

Interprofessional relationships are important in obtaining support from physicians to conduct this type of clinical pharmacy research within their practice. In this study, we tested such a partnership between pharmacists and physicians in the management of TB. The pharmacist joined the healthcare team for implementation of this study; there was only one pharmacist on this team. Five physicians (specialists in pneumophtisiology) were also involved, all of whom understood the importance of healthcare professionals working in collaborative practice.

\section{Statistical analysis}

Descriptive statistics were used to analyze the data collected. Data were analyzed using IBM SPSS version 20.0 (IBM Corporation, Armonk, NY, USA).

\section{Results}

\section{Patient characteristics}

Our study included 130 patients, among whom 28.5\% received PIs. The population studied were on average aged $38.1 \pm 12.9$ years, and the sex ratio was 1.3 males per female.

\section{DRPs}

The DRPs encountered were dominated by drug-drug interactions (DDIs) (26.4\%), noncompliance with the recommendations $(24.5 \%)$, and adverse effects $(24.5 \%)$ (Table 1). Two main types of DDIs were detected. The first type of DDI is a common occurrence, especially with rifampicin (an enzyme inducer). This anti-TB drug is associated with a potential decrease in the plasma concentrations of several drugs. The risks include decreasing drug effectiveness (with metronidazole, albendazole, fluconazole, prednisone, tetracosactide) or the occurrence of convulsion (with valproic acid). The second type of DDI was at the level of absorption of various drugs (fluconazole + rifampicin, esomeprazole + fluconazole, aluminium phosphate + prednisolone + omeprazole, omeprazole + aluminum phosphate). The most frequent DDIs involved PIs for the clinical monitoring of therapeutic response and eventual dose adjustment of drugs associated with rifampicin. Other DDIs required spacing between administration of associated drugs.

A total of $56.1 \%$ of DRPs were identified during medical visits and $43.9 \%$ after the analysis of patient records.

\section{Proportion of anti-TB drugs involved in DRPs}

Anti-TB drugs were involved in $40.3 \%$ of DRPs (Table 2). Other drugs associated with anti-TBs, involved with $59.7 \%$ of DRPs, were classified as level 1 (main group) of the anatomical therapeutic chemical classification system.

\section{Types of PI}

PIs were mainly constituted of proposals regarding parameters for monitoring the effectiveness and safety of treatments $(52.7 \%)$ and were of the clinical monitoring (36.9\%)

Table I Detected drug-related problems

\begin{tabular}{ll}
\hline Drug-related problem & $\mathbf{n ~ ( \% )}$ \\
\hline Drug-drug interaction & $\mathrm{I} 5(26.4)$ \\
Noncompliance with recommendations & $\mathrm{I} 4(24.5)$ \\
Adverse effect & $\mathrm{I} 4(24.5)$ \\
Treatment not received & $5(8.7)$ \\
Drug not indicated & $3(5.3)$ \\
Underdosing & $2(3.5)$ \\
Cost of treatment & $2(3.5)$ \\
Nonconformity with procedure & $\mathrm{I}(\mathrm{I} .8)$ \\
Overdose & $\mathrm{I}(\mathrm{I} .8)$ \\
Total & $57(100)$ \\
\hline
\end{tabular}


Table 2 Proportion of antituberculosis drugs associated with drug-related problems

\begin{tabular}{|c|c|c|c|}
\hline Pharmacotherapeutic group & Medicine & n (\%) & Total group (\%) \\
\hline \multirow[t]{4}{*}{ Antituberculosis drugs } & Rifampicin & $16(28)$ & $23(40.3)$ \\
\hline & Isoniazid & $4(7)$ & \\
\hline & Ethambutol & $2(3.5)$ & \\
\hline & Streptomycin & $\mathrm{I}(\mathrm{I} .8)$ & \\
\hline \multirow[t]{5}{*}{ Digestive tract and metabolism } & Omeprazole & $7(12)$ & $12(20.9)$ \\
\hline & Esomeprazole & $2(3.5)$ & \\
\hline & Sucralfate & $\mathrm{I}(\mathrm{I} .8)$ & \\
\hline & Vitamin complex & I (I.8) & \\
\hline & Activated attapulgite mormoiron & $\mathrm{I}(\mathrm{I} .8)$ & \\
\hline \multirow[t]{5}{*}{ Other antiinfectives } & Cotrimoxazole & $4(7)$ & II (19.1) \\
\hline & Ceftriaxone & $3(5)$ & \\
\hline & Efavirenz & $2(3.5)$ & \\
\hline & Tenofovir & $\mathrm{I}(\mathrm{I} .8)$ & \\
\hline & Fluconazole & $\mathrm{I}(\mathrm{I} .8)$ & \\
\hline \multirow[t]{2}{*}{ Blood and blood-forming organs } & Enoxaparin & $2(3.5)$ & $3(5.3)$ \\
\hline & Ferrous fumarate & $\mathrm{I}(\mathrm{l} .8)$ & \\
\hline \multirow[t]{2}{*}{ Nervous system } & Tramadol & $\mathrm{I}(\mathrm{I} .8)$ & $2(3.6)$ \\
\hline & Diazepam & $\mathrm{I}(\mathrm{I} .8)$ & \\
\hline \multirow[t]{2}{*}{ Systemic hormones } & Prednisone & $\mathrm{I}(\mathrm{I} .8)$ & $2(3.6)$ \\
\hline & Prednisolone & $\mathrm{I}(\mathrm{I} .8)$ & \\
\hline Respiratory system & Oxomemazine & $\mathrm{I}(\mathrm{I} .8)$ & \\
\hline Musculoskeletal system & Ketoprofen & $\mathrm{I}(\mathrm{I} .8)$ & \\
\hline Cardiovascular system & Furosemide & $\mathrm{I}(\mathrm{I} .8)$ & \\
\hline Antiparasitics & Quinine & I (I.8) & \\
\hline Total & & $57(100)$ & \\
\hline
\end{tabular}

and biological monitoring (15.8\%) types. Proposals for therapeutic choice $(28.1 \%)$ were added therapy $(8.7 \%)$ and treatment discontinuation (19.4\%) (Table 3).

\section{Clinical impact of Pls and acceptance rate by physicians}

All interventions made were accepted by physicians. Most of these interventions were listed as $\mathrm{PI}_{1}(59.6 \%)$, that is, with significant clinical impact or $\mathrm{PI}_{0}(26.3 \%)$, without direct clinical impact. Interventions with very significant clinical impact $\left(\mathrm{PI}_{2}\right)$ accounted for $14.1 \%$ of PIs (Table 4 ).

Table 3 Types of pharmaceutical intervention

\begin{tabular}{lll}
\hline Pharmaceutical intervention & $\mathbf{n}(\%)$ & Total (\%) \\
\hline $\begin{array}{l}\text { Proposals for monitoring parameters of treatment effectiveness } \\
\text { and safety }\end{array}$ & 2 I (36.9) & $30(52.7)$ \\
$\quad$ Clinical monitoring & $9(15.8)$ & \\
$\quad$ Biological monitoring & & \\
Therapeutic choice proposals & II (I9.4) & I6 (28.I) \\
Stop treatment & $5(8.7)$ & \\
Add therapy & $5(8.7)$ & \\
Posological adaptation & $5(8.7)$ & \\
Accuracy of administrative procedures & I (I.8) \\
Information on nonregulatory compliance & $57(100)$ & \\
Total &
\end{tabular}

Practical examples of DRPs and PIs carried out in our study are presented in Table 5.

\section{Discussion Principal DRPs}

Pharmacists are responsible for ensuring the proper use of medication through the detection of DRPs. In our study, 57 DRPs were detected, of which the main one was DDIs (26.4\%). Hospitalized patients typically experience polypharmacy and in our study, most patients were hospitalized for complications of TB, which require the use of several drugs, thereby causing these DDIs. The effect of rifampicin, a strong cytochrome $\mathrm{P} 450$ inducer, contributes to this high rate of DDIs. In a study conducted in South Africa, the authors

Table 4 Clinical impact and acceptance rate of pharmaceutical interventions

\begin{tabular}{ll}
\hline $\mathbf{P I}$ & $\mathbf{N}(\%)$ \\
\hline Acceptance rate & $57(100)$ \\
Clinical impact of PI & \\
$\mathrm{PI}_{0}$ (without direct clinical impact) & $15(26.3)$ \\
$\mathrm{PI}_{1}$ (significant clinical impact) & $34(59.6)$ \\
$\mathrm{PI}_{2}$ (very significant clinical impact) & $8(14.1)$ \\
\hline
\end{tabular}

Abbreviation: $\mathrm{PI}$, pharmaceutical intervention. 
Table 5 Examples of detected DRPs and Pls during our study

\begin{tabular}{|c|c|c|}
\hline Type of problem & Examples of DRPs & Pls \\
\hline Drug-drug interaction & Rifampicin with valproic acid & $\begin{array}{l}\text { Undertake clinical monitoring and adapt } \\
\text { valproic acid dosage during treatment } \\
\text { with rifampicin, if possible }\end{array}$ \\
\hline $\begin{array}{l}\text { Noncompliance with } \\
\text { drug choice according } \\
\text { to reference documents }\end{array}$ & $\begin{array}{l}\text { Prescription of corticosteroid (prednisone) in a patient } \\
\text { receiving thiazide diuretic (hydrochlorothiazide) and not } \\
\text { receiving potassium }\end{array}$ & Add potassium \\
\hline Adverse reactions & $\begin{array}{l}\text { Prescription of two nephrotoxic drugs (tenofovir and } \\
\text { streptomycin) in a patient with creatinine clearance } \\
\text { of } 18 \mathrm{~mL} / \mathrm{min}\end{array}$ & $\begin{array}{l}\text { Replace tenofovir with zidovudine } \\
\text { and monitor renal function }\end{array}$ \\
\hline Treatment not received & $\begin{array}{l}\text { Patient did not receive treatment (enoxaparin) for } 2 \text { days } \\
\text { owing to prescription nonrenewal }\end{array}$ & Prescribe enoxaparin \\
\hline Underdosing & $\begin{array}{l}\text { Patient receiving sucralfate for the treatment of } \\
\text { gastroduodenal ulcer, I packet } 2 \text { times/day; recommended } \\
\text { dosage is I packet } 4 \text { times/day }\end{array}$ & Take the drug at the recommended dose \\
\hline Drug not indicated & $\begin{array}{l}\text { Patient still receiving antitussive (oxomemazine) although } \\
\text { no longer coughing }\end{array}$ & Stop the medication \\
\hline Cost of treatment & $\begin{array}{l}\text { Prescription of antigastric secretory (omeprazole) and } \\
\text { topical (aluminum phosphate) medications for the prevention } \\
\text { of peptic ulcers in a patient receiving corticosteroid }\end{array}$ & $\begin{array}{l}\text { Stop the topical drug because the } \\
\text { antisecretory medication is sufficient }\end{array}$ \\
\hline $\begin{array}{l}\text { Regulatory } \\
\text { noncompliance }\end{array}$ & Patient's treatment plan has not been completed & $\begin{array}{l}\text { Always complete the treatment card after } \\
\text { administration of a pharmaceutical agent }\end{array}$ \\
\hline Overdose & $\begin{array}{l}\text { Prescription of fixed-dose combination rifampicin/isoniazid/ } \\
\text { pyrazinamide/ethambutol } 4 \text { tablets single dose, in a } \\
65 \mathrm{~kg} \text { patient with creatinine clearance of } 18 \mathrm{~mL} / \mathrm{min}\end{array}$ & $\begin{array}{l}\text { Change doses of isoniazid ( } 4 \mathrm{mg} / \mathrm{kg} / \text { day }) \text {, } \\
\text { Pyrazinamide ( } 15 \mathrm{mg} / \mathrm{kg} / \text { day }) \text {, and } \\
\text { ethambutol ( } 10 \mathrm{mg} / \mathrm{kg} / \text { day })\end{array}$ \\
\hline
\end{tabular}

Abbreviations: DRPs, drug-related problems; Pls, pharmaceutical interventions.

showed that there were significant potential interactions between anti-TB drugs and other medications that shared various toxicities. ${ }^{18}$ According to Becker et al, DDIs increase morbidity and mortality and are responsible for hospitalization or prolongation of hospitalization. ${ }^{19}$

The DRPs found in our study also involved noncompliance with recommendations (24.5\%). In Côte d'Ivoire, the care of TB patients is dictated by recommendations made by the NTP, which have been widely disseminated to physicians. Our result is comparable to that of Démange, whose care unit found that noncompliance with recommendations was the most common DRP in $28.6 \%$ of interventions. ${ }^{20}$ The rate of $24.5 \%$ found in our study involved both anti-TB drugs as well as other drugs associated with TB treatment.

Adverse effects constituted 24.5\% of DRPs in this study. TB quadritherapy is frequently the cause of adverse effects. Indeed, Vieira and Gomes found that $12.8 \%$ of adverse effects were related to intake of anti-TB drugs. ${ }^{21}$ A study in a pulmonology department of Algeria reported that $20.8 \%$ of patients undergoing TB treatment experienced adverse effects. ${ }^{22}$ The presence of comorbidities and/or TB complications requires support in the form of prescriptions of other pharmaceutical agents that do not cause or exacerbate adverse effects in association with anti-TB drugs.
During our study, nearly $56 \%$ of problems with prescriptions were detected during medical rounds. The study of Kucukarslan et al in a medical unit showed that a pharmacist's participation in medical visits resulted in a reduction of medication errors by $78 \% .{ }^{23}$

\section{Profiles of drugs}

The drugs used for interventions throughout the course of our study belonged to several pharmacotherapeutic groups. Those most frequently cited in the literature were also present in our study. Medication classes of the nervous and cardiovascular systems, alimentary tract and metabolism, anti-infectives, and drugs of the blood and blood-forming organs are the most cited in studies on PIs. ${ }^{9}$ Anti-infectives, with 59.4\%, were the most frequently associated with DRPs, with a predominance of anti-TB drugs found in $40.3 \%$ of DRPs. This result concurs with those of Chabia et a ${ }^{24}$ who showed that anti-infectives constituted $31 \%$ of the reasons for interventions. The most encountered drugs among detected DRPs were rifampicin (28\%), omeprazole $(12 \%)$, isoniazid $(7 \%)$, cotrimoxazole $(7 \%)$, and ceftriaxone $(5 \%)$. In the patient care unit, the profile of medicines used depends on the specific pathologies. Rifampicin is one of the basic molecules used in the treatment of drug-susceptible TB. Its role in DDIs, owing to 
its inductive effect on cytochrome P450, likely explains its involvement in DRPs.

\section{Pls carried out}

In our study, PIs were mainly concerned with proposals for monitoring treatment effectiveness and safety in $52.7 \%$ of cases. Proposals for therapeutic choice in terms of stopping or adding treatment were made in $28.1 \%$. Approximately $8.7 \%$ of PIs were for dose adjustments. Démange found that PIs were dominated by discontinuing treatment (39.3\%) and dose adjustments $(28.6 \%)$, and PIs related to therapeutic monitoring represented $1.4 \% .{ }^{20}$ Gaillard et al reported that PIs were related to treatment substitutions (50\%), optimization of administration methods (24\%), dose adjustment (11\%), and therapeutic monitoring (4\%). ${ }^{25}$ These differences can be explained by the differing medical contexts of these studies. Indeed, Démange conducted his study in several medical and surgical services, ${ }^{20}$ whereas ours was carried out in a single service. The PIs performed by Gaillard et al focused on the treatment of patients upon admission, ${ }^{25}$ while ours involved all prescriptions after hospital admission of the patient until their release from the hospital.

\section{Relevance of Pls}

The acceptance rate of PIs in this study was $100 \%$. This very high rate was comparable to those found in the literature, especially in the studies of Tanguy-Goarin and Mugnier $(93.6 \%)^{17}$ and Démange $(89.3 \%) .{ }^{20}$ This can be interpreted as a sign of the relevance of PIs and the proper use of pharmacists' knowledge to improve patient health care. All these studies have confirmed not only interest in using the expertise of pharmacists within the medication system but also the fact that the presence of a pharmacist in the healthcare unit increases the number of PIs and their rates of acceptance. ${ }^{26}$

Interventions were rated $\mathrm{PI}_{1}$ in $59.6 \%$ of cases, that is, with significant clinical impact. Listed $\mathrm{PI}_{2}$ interventions with a very significant clinical impact accounted for $14.1 \%$. This further demonstrates the relevance of PIs. A study by Jenn et al found that $63.3 \%$ of interventions had a significant impact and $22.8 \%$ a very significant impact. ${ }^{27}$

\section{Role of the pharmacist}

Multidrug-resistant TB and extensively drug-resistant TB have been identified as serious public health threats that call for increased efforts in managing $\mathrm{TB} .{ }^{28}$ It has been suggested that pharmacists should play a greater role in TB treatment by promoting treatment adherence; assessing patients for risk factors for resistant disease; providing information about disease control and prevention; and monitoring for effectiveness, adverse effects, and DDIs. ${ }^{29}$ Therefore, pharmaceutical care in TB management is a complex intervention as there are various PIs contributing to the control of this disease. Our study revealed this complexity in the multifaceted nature of the PIs carried out. We considered PIs in an inpatient setting with a need to improve therapeutic outcomes and to prevent iatrogenic events. In the work of Venkatapraveen et al, PIs were found to have a significant influence on the healthcare outcomes of TB patients; the sputum conversion rate in their intervention group was $80.71 \%$ versus $43.86 \%$ in the control group. ${ }^{30}$ In our study, participation by the pharmacist in the management of TB allowed for detection of the DRPs faced by physicians with respect to their current practice, the main one being DDIs. The pharmacist's role is therefore to provide physicians with expertise in the management of DDIs and other DRPs. Medication history during patient admission and counseling sessions at the end of hospitalization can be integrated into PIs in future studies.

The management of patients with TB requires a multidisciplinary team of healthcare professionals. Pharmacists form a crucial part of such teams and can be involved with different stages in the value chain for TB control using effective PIs. Therefore, pharmacists should be urged to participate in the management of TB at hospital healthcare units in Côte d'Ivoire, where they currently do not provide pharmaceutical care at TB inpatient settings.

\section{Study limitations}

The first limitation of this pilot study is the participation of a small number of healthcare professionals. Only physicians in this pneumophtisiology department who were already in agreement with the importance of pharmacists working in collaborative practice on a healthcare team participated in the study. Only one pharmacist was available for prescription reviews; therefore, because of time scarcity, many drug prescriptions were not reviewed. To provide more time per patient and per prescription, more pharmacists would be needed. In addition, enhanced pharmacist-patient communication was not sufficiently implemented. This type of communication is important for drug reconciliation and therapeutic patient education.

The study was conducted in one pneumophtisiology department of Côte d'Ivoire, which may restrict generalization of the profile of DRPs and PIs related to TB inpatient treatment. This pilot study was carried out within a relatively short period of time (10 months with a break owing to temporary closure of the department for sterilization after two cases of 
resistant strain Pseudomonas aeruginosa infection). DRPs were identified by assessing problems related to prescriptions. Problems related to patient factors (patients' behavior and attitude toward medications, and beliefs and concerns about medications) and problems related to organizational factors were not investigated. The clinical impact of accepted PIs was not correlated to patient healthcare outcomes but was based only on physicians' points of view and on the type of rating.

\section{Conclusion}

The presence of a pharmacist at inpatient setting has contributed to the prevention and resolution of problems related to the pharmacotherapeutic management of TB. The PIs in this study were proved relevant by their high acceptance rate and significant clinical impact. Pharmacists can position themselves as major players in the therapeutic management of TB inpatient. The management of TB is multidisciplinary; it is therefore necessary that each healthcare professional can act effectively at their own level to fight against the disease. Pharmacists must invest in increasing their role and positioning themselves fully as key players in the management of TB at inpatient settings in Côte d'Ivoire.

\section{Acknowledgments}

The authors would like to thank the management at the Abidjan Cocody Teaching Hospital and the Medical Scientific Department, which allowed them to conduct this study. Also, they would like to extend their thanks to the head of the pneumophtisiology department.

\section{Disclosure}

The authors report no conflicts of interest in this work.

\section{References}

1. World Health Organization. Global tuberculosis report 2014. WHO Geneva 2014. Available from: http://apps.who.int/iris/bitstream/10665 /137094/1/9789241564809_eng.pdf. Accessed October 10, 2015.

2. Ait Belghiti F, Antoine D. Epidemiology of tuberculosis in France 2013. Bull Epidémiol Hebd 2015;(9-10):164-171. Available from: http://www. invs.sante.fr/beh/2015/9-10/2015_9-10_3.html. Accessed October 10, 2015. French.

3. Kwon YS, Kim YH, Suh GY, et al. Treatment outcomes for HIVuninfected patients with multidrug-resistant and extensively drugresistant tuberculosis. Clin Infect Dis. 2008;47(4):496-502.

4. World Health Organization. Involving private practitioners in tuberculosis control: issues, interventions, and emerging policy framework. WHO Geneva 2001. WHO/CDS//TB/2001.285. Available from: http:// apps.who.int/iris/bitstream/10665/66733/1/WHO_CDS_TB_2001.285. pdf. Accessed October 20, 2015.

5. Hopewell PC, Pai M, Maher D, Uplekar M, Raviglione MC. International standards for tuberculosis care. Lancet Infect Dis. 2006;6(11):710-725.

6. Ouédraogo M, Kouanda S, Boncoungou K, et al. Therapeutic itinerary of bacillary tuberculosis patients detected in two treatment centers for tuberculosis in Burkina Faso. Int J Tuberc Lung Dis. 2006; 10(2):184-187. French.
7. Gillespie U, Alassaad A, Henrohn D, et al. A comprehensive pharmacist intervention to reduce morbidity in patients 80 years or older: a randomized controlled trial. Arch Intern Med. 2009;169(9):894-900.

8. Schnipper JL, Kirwin JL, Cotugno MC, et al. Role of pharmacist counseling in preventing adverse drug events after hospitalization. Arch Intern Med. 2006;166(5):565-571.

9. Kausch C, Tan Sean P, Boelle PY, et al. Economic consequences and acceptance of a clinical pharmacist in a surgery ward. J Pharm Clin. 2005;24(2):90-97. French.

10. Conort $\mathrm{O}$, Bedouch $\mathrm{P}$, Juste $\mathrm{M}$, et al. Validation of an instrument for the codification of clinical pharmacy interventions. JPharm Clin. 2004; 23(3):141-147. French.

11. Vidal 2012: the dictionary. 88th ed. Vidal, eds. Paris 2012, 3000 p.

12. Dorosz P, Vital-Durand D, Le Jeune C. Dorosz-Practical Guide of drugs 32nd ed. Maloine, eds. Paris 2013. French.

13. French National Agency for Medicines and Health Products Safety (ANSM). Thesaurus of drug-drug interactions 2013. Available from: http://www.ansm.sante.fr. Accessed October 20, 2013. French.

14. Ministry of Health and the fight against AIDS-Ivory Coast. Compilation of national treatment protocols of pathologies, 2013 edition; 196p. Available from: http://apps.who.int/medicinedocs/documents/s20987fr/ s20987fr.pdf. Accessed March 4, 2014. French.

15. Guignon AM, Grain F, Allenet B, et al. Assessment of the clinical impact of pharmacists'recommendations in a medical care unit. J Pharm Clin. 2001;20(2):118-123. French.

16. Bayliff CD, Einarson TR. Physician assessment of pharmacists' interventions: a method of estimating cost avoidance and determining quality assurance. Can J Hosp Pharm. 1990;43(4):167-171.

17. Tanguy-Goarin C, Mugnier N. Clinical pharmacist activity in an oncology and aematology unit significantly improves and secure patient care. Le Pharmacien hospitalier et clinicien. 2011;46(1):4-12. French.

18. Wasserman S, Meintjes G. The diagnosis, management and prevention of HIV-associated tuberculosis. S Afr Med J. 2014;104(12): 886-893.

19. Becker ML, Kallewaard M, Caspers PW, Visser LE, Leufkens HG, Stricker BH. Hospitalisations and emergency department visits due to drug-drug interactions: a literature review. Pharmacoepidemiol Drug Saf. 2007;16(6):641-651.

20. Démange C. Pharmaceutical analysis of prescriptions in care units using the French Society of Clinical Pharmacy's intervention sheet. J Pharm Clin. 2007;26(1):45-52. French.

21. Vieira DE, Gomes M. Adverse effects of tuberculosis treatment: experience at an outpatient clinic of teaching hospital in the city of Sao Paulo, Brazil. J Bras Pneumol. 2008;34(12):1049-1055.

22. Terniche M, Nafti S. Problem of management of intolerance of antituberculosis drugs. Rev Mal Respir. 2009;26(HS1):134. French.

23. Kucukarslan SN, Peters M, Mlynarek M, Nafziger DA. Pharmacists on rounding teams reduce preventable adverse drug events in hospital general medicine units. Arch Intern Med. 2003;163(17): 2014-2018.

24. Chabia Y, Galveza O, Granetb JP, Mattonc T, Merlina C, Rey P. Evaluating the editorial quality of drug prescriptions and pharmaceutical interventions in metz legouest military hospital. Médecine et armées. 2012;40:281-288. French.

25. Gaillard K, Bohand X, Beranger C, Boulliat C, Guevel C. Evaluation of pharmaceutical interventions at Sainte-Anne military hospital as part of a unit dose drug daily distribution system. J Pharm Clin. 2006;25(1):39-47. French.

26. Bedouch P, Allenet B, Labarere J, et al. Diffusion of pharmacist interventions within the framework of clinical pharmacy activity in the clinical ward. Thérapie. 2005;60(5):515-522. French.

27. Jenn J, Debruyne AL, Barone AL, et al. Impact of medical and pharmaceutical intervention on the health status of people aged over 75 years, three months after their release after hospitalization for Geriatric healthcare and rehabilitation 2010. Available from: http:// www.has-sante.fr/portail/upload/docs/application/pdf/2010-04/po269. pdf. Accessed April 6, 2015. French. 
28. Gandhi NR, Nunn P, Dheda K, et al. Multidrug-resistant and extensively drug-resistant tuberculosis: a threat to global control of tuberculosis. Lancet. 2010;375(9728):1830-1843.

29. Mkele G. The role of the pharmacist in TB management. S Afr Pharm J. 2010;77(2):18-21.
30. Venkatapraveen A, Rampure MV, Patil N, Hinchageri SS, Lakshmi DP. Assessment of clinical pharmacist intervention to improve compliance and health care outcomes of tuberculosis patients. Der Pharmacia Lettre. 2012;4(3):931-937.

\section{Publish your work in this journal}

Therapeutics and Clinical Risk Management is an international, peerreviewed journal of clinical therapeutics and risk management, focusing on concise rapid reporting of clinical studies in all therapeutic areas, outcomes, safety, and programs for the effective, safe, and sustained use of medicines. This journal is indexed on PubMed Central, CAS,
EMBase, Scopus and the Elsevier Bibliographic databases. The manuscript management system is completely online and includes a very quick and fair peer-review system, which is all easy to use. Visit http://www.dovepress.com/testimonials.php to read real quotes from published authors. 